\title{
A Miniaturized Patch Antenna Designed and Manufactured Using Slot's Technique for RFID UHF Mobile Applications
}

\author{
Younes El Hachimi, Yassine Gmih, EI Mostafa Makroum, Abdelmajid Farchi \\ Laboratory of Engineering, Industrial Management and Innovation \\ University Hassan 1st, Faculty of Sciences and Technologies, Morocco
}

\begin{tabular}{l} 
Article Info \\
\hline Article history: \\
Received Jan 4, 2018 \\
Revised Jul 19, 20 \\
Accepted Jul 22, 201 \\
\hline Keyword: \\
Bandwidth \\
Compact antenna \\
Gain \\
Input Impedance \\
Return loss \\
RFIDUHFreader \\
Slots \\
VSWR
\end{tabular}

Keyword:

Bandwidth

Compact antenna

Input Impedance

Return loss

Slots

VSWR

\begin{abstract}
In this research work, a novel compact antenna with rectangular slots is presented for radio frequency identification (RFID) handled applications in the ultrahigh frequency (UHF) band that can be manufactured and integrated into RFID readers without difficult. A prototype demonstrating the aforementioned features was constructed and measured. The proposed antenna is fed by $50-\Omega$ coaxial cable and printed on a $1.6 \mathrm{~mm}$ thick FR4 substrate which has a small size and occupies a volume of $68 \times 66 \times 1.6 \mathrm{~mm}^{3}$. The patch, the feed-line and ground plane are made of PEC (Perfect Electric Conductor) with a thickness of $0.035 \mathrm{~mm}$. Measured results indicate that the proposed antenna has a good impedance matching characteristic ranging from 889 to $939 \mathrm{MHz}$, which covers the USA RFID-band $(902-928 \mathrm{MHz})$, the Chinese RFID-operating-band (920-924.5MHz), and the Korea and Japan RFID-band (917-923.5MHz). These results were achieved by the insertion of slots in the compact structure of the antenna. The electromagnetic simulators HFSS (High Frequency structure simulator) and CST (Computer Simulation Technology) microwave studio were used for the design, modeling and simulation of the antenna. The focus of the study of our antenna was on the parameters of return loss, bandwidth, Voltage Standing Wave Ratio (VSWR), input impedance and gain.
\end{abstract}

Copyright () 2018Institute of Advanced Engineering and Science. All rights reserved.

\section{Corresponding Author:}

Younes El Hachimi,

Laboratory of Engineering, Industrial Management and Innovation,

Faculty of Sciences and Technologies, Settat- Morocco, University Hassan $1^{\text {st }}$,

Road of Casablanca, Mail Box: 577, Km 3, Settat- Morocco.

Email: elhachimi.younes1@gmail.com

\section{INTRODUCTION}

The radio frequency identification technology (RFID) is the current dominating technology in wireless communication because it provides a much more flexible way of non-contact communication. As of late, RFID systems have been receiving an increasing amount of interest [1]-[2] both from the scientific and industrial communities. These systems are founded on saving and extracting wireless data that concern the object to identify. The interchange of data and information is done by using radiofrequency electromagnetic fields. An RFID system generally contains a reader, a tag, and a data processing system. Figure 1 exhibits the functioning of the RFID system [3]. The energy is transmitted by the reader (fitted with an antenna) to the RFID Tag by the way of radio-frequency waves. This energy is used to activate the tag by sending an information request to which the tag located within its magnetic field responds [4], [5]. The reader is usually connected to a host data processing system that embodies the information of the identified item and communicates with other remote data processing systems [6].

In reference to the ISO (International Standardization Organization) standard, the RFID frequency bands are the LF (Low Frequency) at $125 \mathrm{kHz}$ [7], the $\mathrm{HF}$ (High Frequency) band at 13.56MHz [8], the UHF band from 860 to $960 \mathrm{MHz}$, [9], and 2.45GHz [10] and 5.8GHz bands [11], [12]. Because of the advantages 
of longer reading distance, fast reading speed and large information storage capability, [13], UHF-RFID system has been acquiring an increasing popularity for many industrial services such as inventory management, tracking, supply chain, and bioengineering applications. However and despite the aforementioned ISO standard, licensed UHF RFID operating frequency bands are allocated within the 860 to $960 \mathrm{MHz}$ band, depending on the geographical region, as for example, ETSI band (865-868 MHz) in Europe, FCC band (902-928 MHz) in North and South America, 920.5-924.5MHz in China, and 917-923.5MHz in Korea and also Japan [14].

The RFID reader antenna is one of the essential constituent elements of an RFID system and its capacity will specify the performance of entire system [15]. The performance of such systems is directly linked to the target application's type and to the antenna's characteristics (shape, dimensions, type of metallization, etc.). Each of these characteristics depends on parameters like resonant frequency, bandwidth, gain, and directivity. The dimensioning of the RFID antenna should take into account the intended usage and the desired resonant frequency [7]. However, the needs for small antenna providing sufficient overall performance is growing due to the increasing demand for small compact wireless devices with high data rate transfer capabilities, low-price and no detrimental effects on human health.

The micro-strip patch antenna, being one of the most significant developments in antenna and electromagnetic history, constitutes a viable solution to the need for increasingly compact antenna. It has attracted considerable interest due to their low fabrication cost, low profile, ease of fabrication, light weight, and compatibility with printed circuits [16], [17]. Due to these advantages, micro-strip patch antenna's uses include portable devices such as mobile phones, laptops etc [18]. The reduction in size that these devices have known in the past decade is driving the focus on smaller more compact micro-strip patch antennas, placing this issue at the frontline of interest for various researchers [19].

Many methods of miniaturization have been employed such as short-circuiting between the patch and the ground plane [20], the augmentation of the relative dielectric constant of the substrate [21], the use of fractal structure [22], the use of metamaterials [23] and remodeling or introducing of slots in the patch (DMS) or the ground plane (DGS) (Slots technique) [24]. In this work, we used the slot technique. It consists of the creation of various resonant structures into an antenna through cutting slots of different geometrical shapes. This technique allows to miniaturize the antenna and to improve his bandwidth. Several studies have recently explored different geometric design configurations for the purpose of bandwidth enhancement and size reduction [25]-[26].

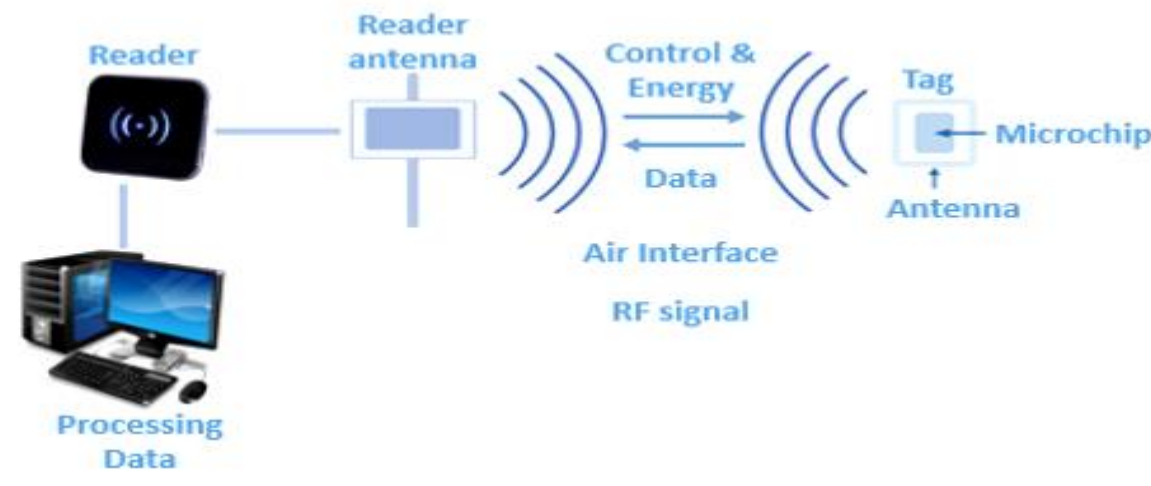

Figure 1. Principle of an RFID system operation [3]

In this paper, a compact and low-profile new patch antenna structure with rectangular slots for RFID UHF reader is proposed. The main purpose of this work is to design a miniature antenna with good characteristics. The compactness was achieved by using the slots technique. The antenna's design was started with the use of a rectangular slot in the patch to achieve adaptation. Then, to improve radiation characteristics such as return loss, bandwidth, and gain, we have integrated subsequent geometrical slots to the patch. The antenna is constituted by a feed line and a patch that comprises numerous geometrical slots. A parametric study was employed to optimize the final design. The obtained results of the proposed antenna were talked over. The last part of the paper presents a comparison between our antenna and other structures. 


\section{ANTENNA DESIGN}

The structure of the proposed antenna and its various parameters are described in Figure 2. It has dimensions of $68 \times 66 \times 1.6 \mathrm{~mm}^{3}$ with compact size and operates in UHB band. It is supplied by a $50 \mathrm{Ohm}$ micro-strip line with a length of $\mathrm{Lf}=25 \mathrm{~mm}$ and width of $\mathrm{Wf}=4.2 \mathrm{~mm}$. The radiating element and the feedline are PECs (Perfect Electric Conductor) $0.035 \mathrm{~mm}$ thick. A photograph of the fabricated antenna is shown in Figure 8. The antenna was manufacturedemploying an FR4 substrate with a relative permittivity of 4.4, loss tangent of 0.025 , and thickness of $\mathrm{h}=1.6 \mathrm{~mm}$. The antenna is constituted by a feed-line, a patch that comprises several radiating slots of different shapes and a ground plane. Dimensions of the patch, slots, ground plane and substrate are regrouped in the Table I. The design process can be divided into three steps with different antenna configurations which are illustrated in Figure 3 as Ant 1, Ant 2 and Ant 3(the proposed antenna), respectively. All These antennas are printed on FR4 substrates with the same volume and with the same ground plane. For the purpose of reach the exact resonant frequency and to rise the return loss, simulations were carried out in 3 iterations, reflecting the gradual insertion of slots in the antenna.

In Ant 1, the antenna design starts with a rectangular slot that was introduced in the patch to achieve adaptation, but the impedance matching was poor and the antenna was not adapted to the desired resonant frequency. In Ant 2, we have modified the shape of the rectangular slot to H-shaped slot to attain the exact resonant frequency. It exhibited a good impedance matching characteristic, reflection coefficient less than 10 $\mathrm{dB}$ with a return loss of $-21 \mathrm{~dB}$ at $917 \mathrm{MHz}$ and a bandwidth of $53 \mathrm{MHz}$ from 890 to $843 \mathrm{MHz}$. However, the return loss must be improved. Therefore, in Ant 3, our proposed antenna, several slots have been embedded to the patch and a geometrical modification of the width of the feed-line has been done to boost the characteristics of the antenna and in order to obtain a good adaptation. As a result, the return loss S11 has been increased.

An impedance bandwidth of $43 \mathrm{MHz}$ ranging from 894 to $937 \mathrm{MHz}$ was achieved in the center frequency of $916.6 \mathrm{MHz}$ with a suitable reflection coefficient of $-45.69 \mathrm{~dB}$. These reflection coefficients simulation characteristics of the three steps were analyzed using the electromagnetic simulator CST Microwave Studio. In order to validate these results, we carried out the study with another simulator (HFSS). Figure 3 shows the return loss of the evolution of our structure. The return loss is improved; it changes from $13.74 \mathrm{~dB}$ at $983 \mathrm{MHz}$ to $-45.69 \mathrm{~dB}$ at $916 \mathrm{MHz}$ by using CST and from $-13.5 \mathrm{~dB}$ at $1 \mathrm{GHz}$ to $-28.89 \mathrm{~dB}$ at $920 \mathrm{MHz}$ by using HFSS.

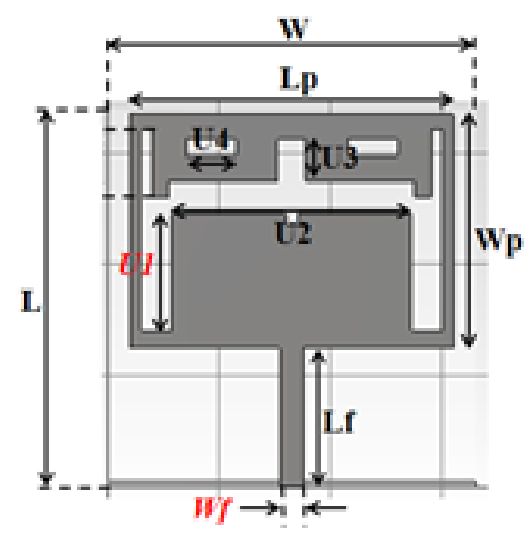

(a)

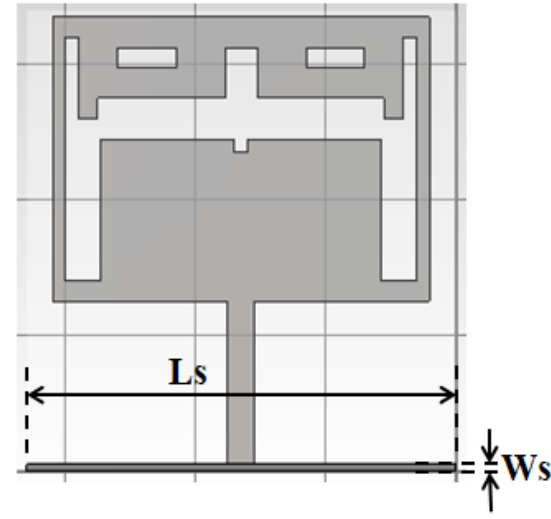

(b)

Figure 2. The proposed antenna configuration: (a) top view and (b) bottom view

Table 1. Dimensions of the proposed antenna

\begin{tabular}{ccccccc}
\hline Parameters & L & W & Lp & Wp & Lf & Wf \\
\hline Dimensions (mm) & 68 & 66 & 58 & 42 & 25 & 4.2 \\
Parameters & Lg & Wg & U1 & U2 & U3 & U4 \\
Dimensions (mm) & 66 & 1 & 24 & 43 & 7.5 & 9 \\
\hline
\end{tabular}




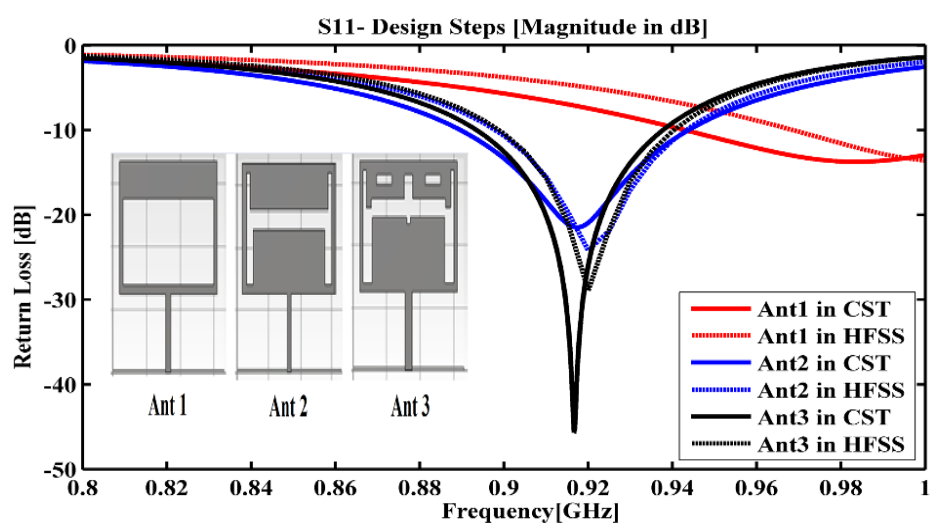

Figure 3. Simulated return loss for Ant 1, Ant 2 and Ant 3 for both simulator (HFSS and CST)

\section{PARAMETRIC STUDY}

To understand the effects of various parameters on the proposed antenna performance, a parametric study is being employed to optimize the final design. The radiating element has two key parameters: "U1", the width of the H-shaped slot's rectangle which can fine-tune the operating frequency and "Wf", the width of the feed-line which influences the reflection coefficient and can improve it. Each physical attribute of the antenna is independently varied, with all other parameters being kept unchanged.

\subsection{The Effect of U1, the Width Of the H-Shaped Slot's Rectangle, on the Return Loss}

The width of the H-shaped slot's rectangle (U1) is optimized because it affects the resonance frequency. The first step in our design is to choose the appropriate width U1 to start with. When U1 increases from 18 to $26 \mathrm{~mm}$, the resonance frequency will be shifted down to a lower frequency and the reflection coefficient S11 improves. As shown in Figure 4, the better result was observed when the value of U1 was $24 \mathrm{~mm}$. The corresponding frequency value was $916.4 \mathrm{MHz}$.

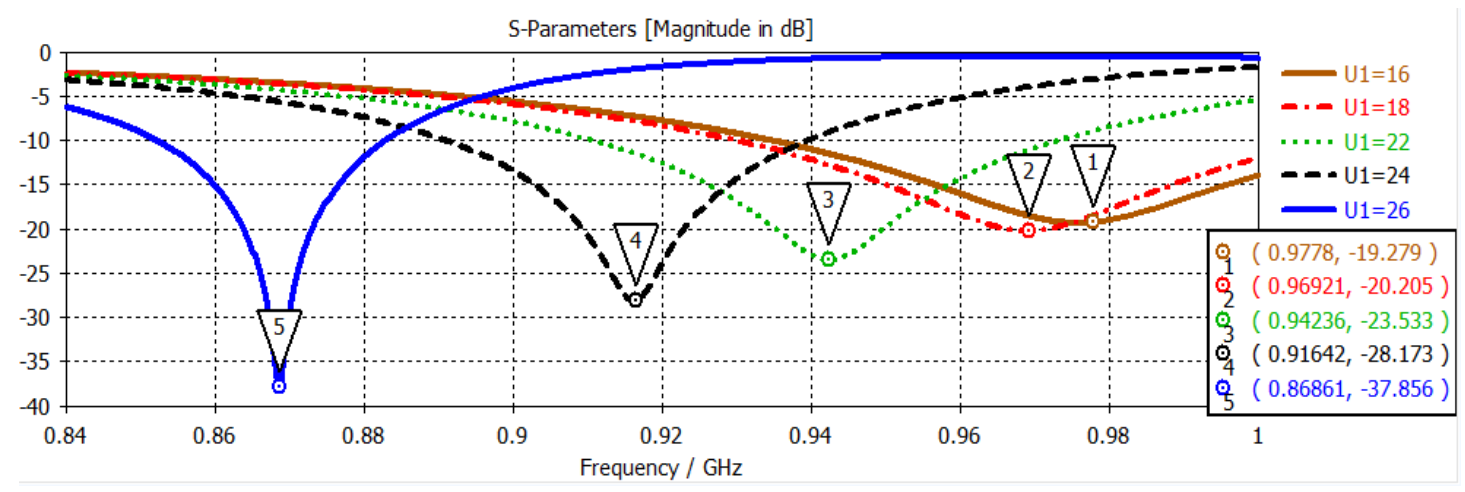

Figure 4. Simulated return loss of the proposed antenna with various U1

\subsection{The Effect of the Feed-line Width Wf on the Return Loss}

After choosing the value of U1, the width of the H-shaped slot's rectangle, it is now feasible to study the effect of Wf, the feed-line's width, on the reflection coefficient. Figure 5 demonstrates the influence of Wf on the return loss. It can be clearly observed from the simulated results that the impedance matching improves and the resonance frequency was shifted slightly to a higher frequency with increasing the width of the feed-line from 3 to $4.4 \mathrm{~mm}$. Starting from Wf=4.6 mm, the return loss decrease. Therefore, a width of 4.2 $\mathrm{mm}$ is selected as the optimum value of Wf with a return loss of -45 at the resonant frequency of $916 \mathrm{MHz}$. 


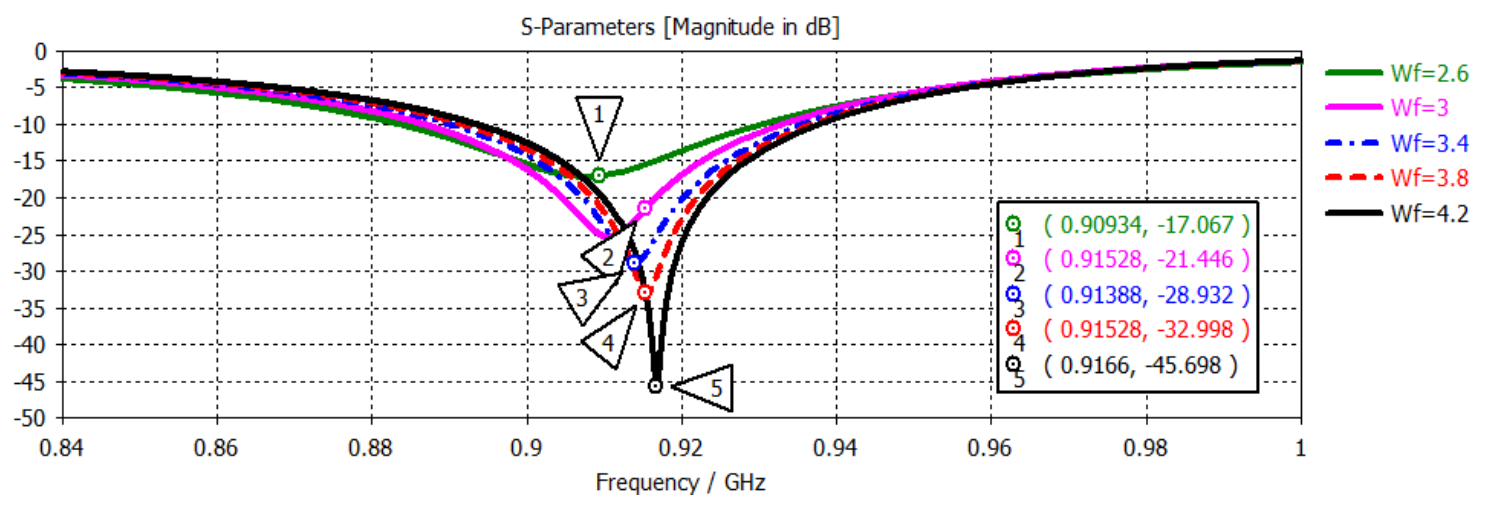

Figure 5. Simulated return loss of the proposed antenna with various Wf

\section{RESULTS AND DISCUSSION}

The goal of this study is to design a new antenna with compact and low profile structure for typical UHF-RFID bands with a good return loss by using the slots technique. The proposed antenna simulations were exacuted utilizing CST Microwave Studio and HFSS electromagnetic simulators. The first one employs the Finite Integration Method (FIM). The second one is based on the Finite Element Method (FEM). To validate the concept proposed above, an antenna operating at $0.918 \mathrm{MHz}$ is fabricated on a $1.6 \mathrm{~mm}$ FR4 substrate as shown in Figure 6.

\subsection{Return Loss}

Figure 6 shows simulated and measured return loss S11 as a function of frequency. We notice that the simulated return loss reaches a value of $-45.69 \mathrm{~dB}$ at $916.6 \mathrm{MHz}$ with a bandwidth of $43 \mathrm{MHz}$ ranging from 894 to $937 \mathrm{MHz}$ in CST, while in HFSS, it reaches a value of $-28.89 \mathrm{~dB}$ with a bandwidth of $42 \mathrm{MHz}$ from 898 to $940 \mathrm{MHz}$ in the center frequency of $920 \mathrm{MHz}$. The measured return loss attains a value of -17.06 $\mathrm{dB}$ at $918 \mathrm{MHz}$ with a bandwidth of $40 \mathrm{MHz}$ extending from 889 to $939 \mathrm{MHz}$ covering a typical UHF RFID bands (USA Band (902-928MHz), the Chinese and Thailand band (920-925MHz), and the Korea and Japan band $(917-923.5 \mathrm{MHz})$ ). These values are less than $-10 \mathrm{~dB}$, this reflects the antenna adaptation.

According to this result, measured and simulated return losses are in good agreement. The slight differences between them are due to the effect of SMA (SubMiniature version A) connector soldering, substrate losses, and measurement circumstances. The measured result justifies and validates the simulated ones and the attained impedance bandwidth of the proposed antenna is $40 \mathrm{MHz}$ ( 889 to $939 \mathrm{MHz}$ ).

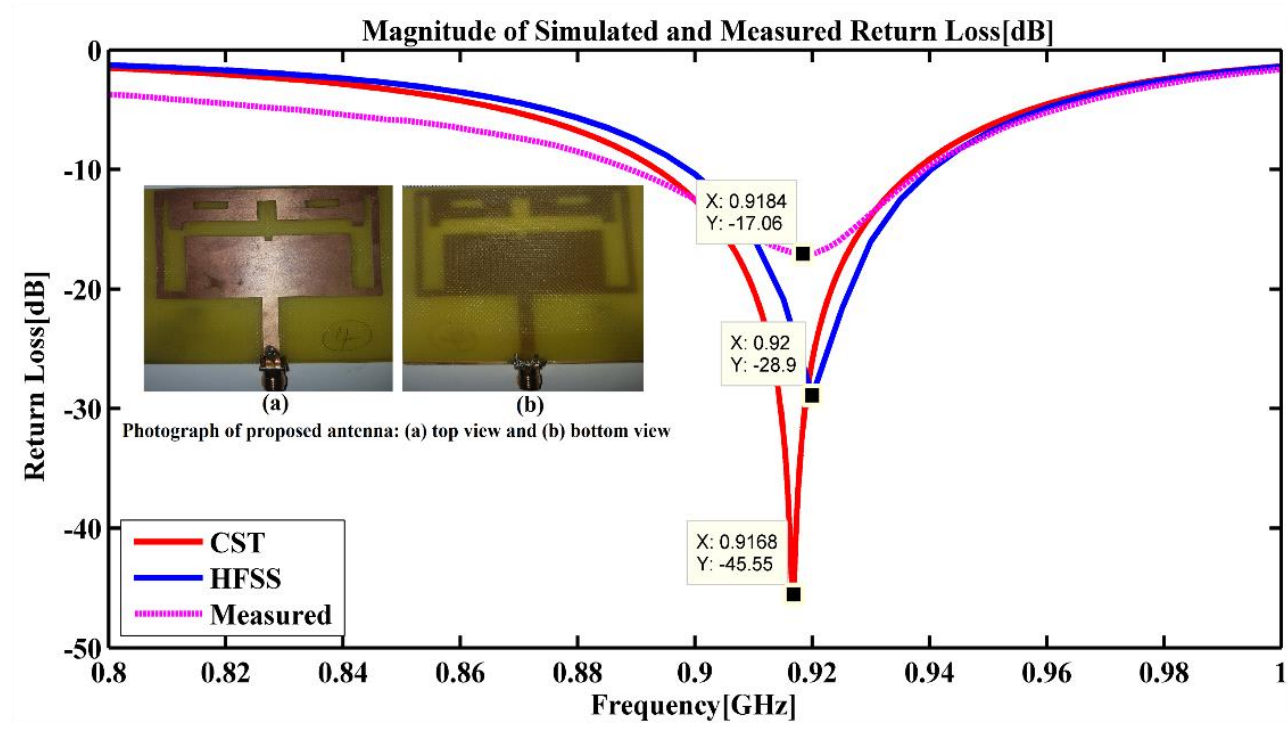

Figure 6. Simulated and measured return loss of the proposed antenna 


\subsection{Voltage Standing Wave Ratio (VSWR) and Input Impedance (Zin)}

To study how well the antenna is impedance matched to the radio or transmission line it is connected to, an important parameter has been simulated: the Voltage Standing Wave Ratio (VSWR). It is a measure of how efficiently radio-frequency power is transmitted from a power source, through a transmission line, into a load. Figure 7 shows the simulated VSWR of our antenna. It is less than 2 (VSWR $<2$ ) over the frequency range of $892-938 \mathrm{MHz}$ and reaches a value of 1.01 at $916.6 \mathrm{MHz}$ in CST, while, in HFSS, it can be observed that the frequency band ranges from 897 to $941 \mathrm{MHz}$ and reaches a value of 1.07 at $920 \mathrm{MHz}$ which demonstrates that the antenna is adapted. Another parameter can prove the adaptation of the antenna: the input impedance. It is clearly seen from Figure 8 that it is equal to $\mathrm{Zin}=(49.59+0.31 \mathrm{j}) \Omega$ at $916.6 \mathrm{MHz}$ resonant frequency in CST and equal to $\mathrm{Zin}=(47.23+2.12 \mathrm{j}) \Omega$ at $920 \mathrm{MHz}$ in HFSS.

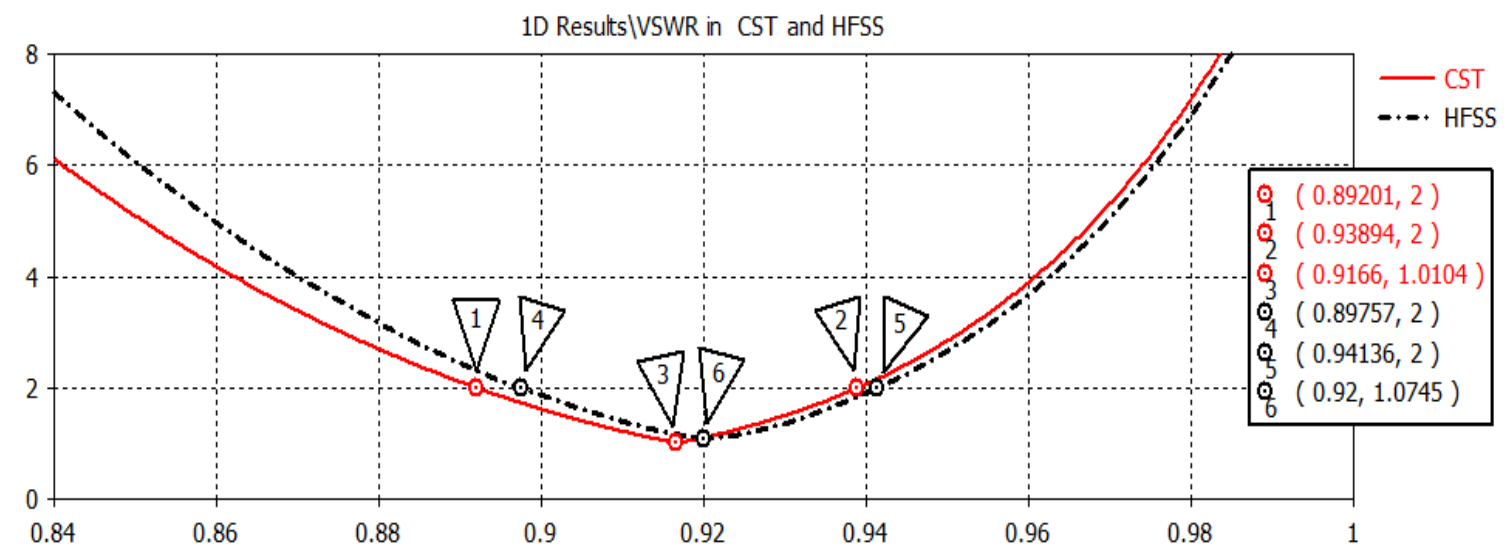

Figure 7. Simulated Voltage Standing Wave Ratio

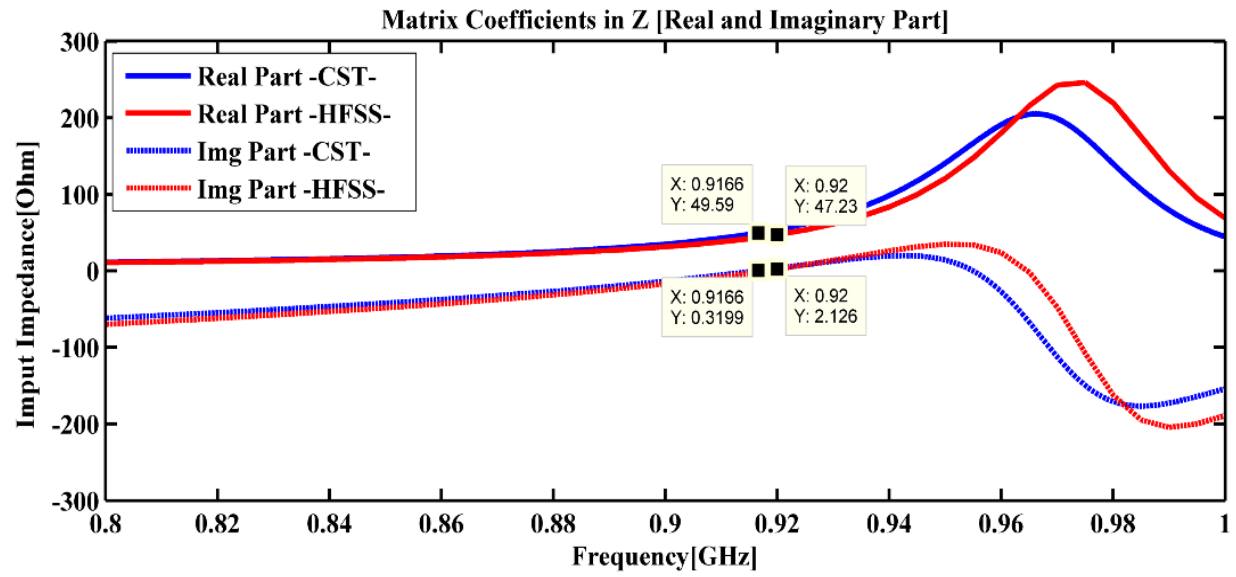

Figure 8. Simulated input impedance of the proposed antenna (a) in CST and (b) in HFSS

\subsection{Radiation Pattern}

The radiation pattern describes how the antenna radiates energy out over long distances in different spatial directions. Figure 9 represents $2 \mathrm{D}$ radiation pattern in CST and HFSS in the two plans E $(\varphi=0)$ and H $(\varphi=90)$ of the proposed antenna at the several typical frequencies $(905 \mathrm{MHz}-915 \mathrm{MHz}-920 \mathrm{MHz})$. It is bidirectional in the two plans for the three frequency. 


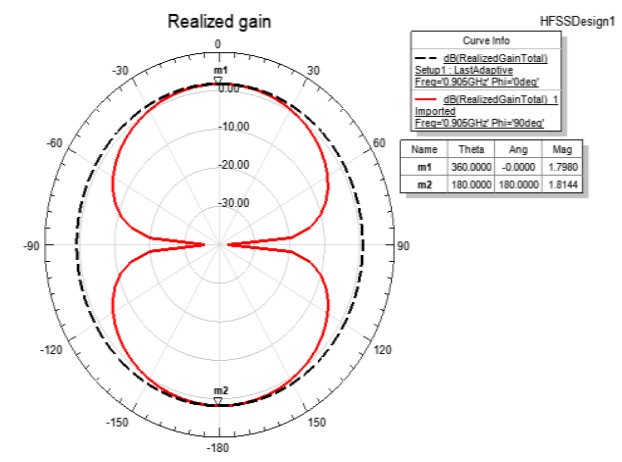

1D Results|Farfields|Pattern

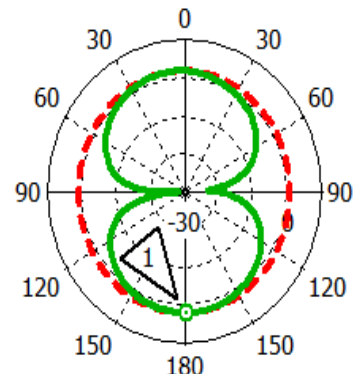

— - farfield $(f=0.905)[1]($ Abs, Phi $=0)$ farfield $(f=0.905)[1]($ Abs, Phi $=90)$

@ $(178.3,1.711)$

$905 \mathrm{MHz}$

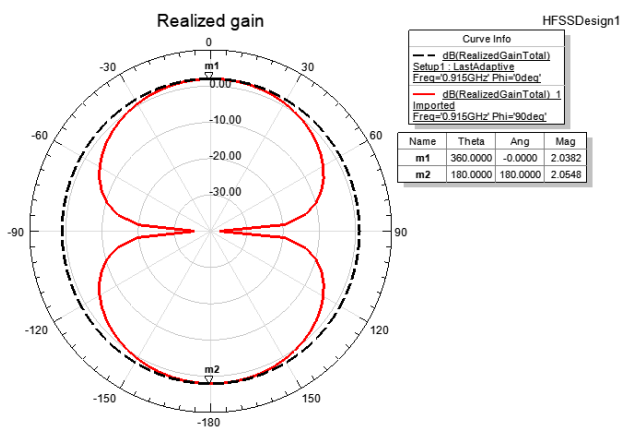

1D Results \Farfields \Pattern

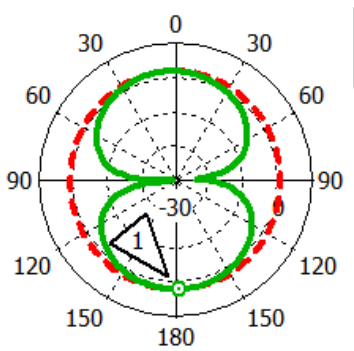

- - farfield $(f=0.915)[1]$ (Abs, $P h i=0)$ farfield $(f=0.915)[1]($ Abs, Phi $=90)$

$\stackrel{9}{1}(178.3,1.77)$

$915 \mathrm{MHz}$

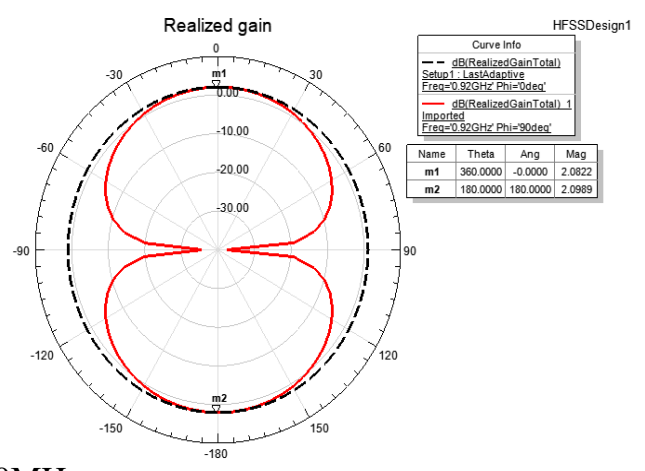

(a)
1D Results $\backslash$ Farfields $\backslash$ Pattern

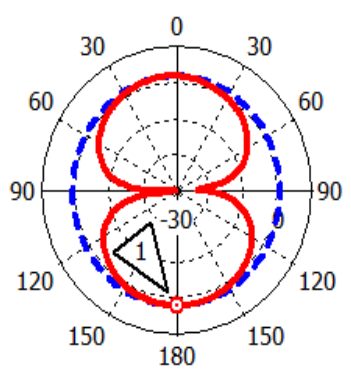

- - • farfield $(f=0.92)[1]($ Abs, Phi $=0)$ farfield $(f=0.92)[1]($ Abs, $P h i=90)$

i $(180,1.713)$

Figure 9. Gain patterns at different resonant frequencies (905-915-920 MHz) in both E- and H-planes (a) in CST and (b) HFSSS

In order to complete the study of the proposed antenna, a calculation of the gain variation over the operating frequency band is performed through the far field by using the two simulators. The graph results in Figure 10 show that the proposed antenna provides a peak gain fluctuated between $1 \mathrm{~dB}$ and $1.76 \mathrm{~dB}$ from 894 to $937 \mathrm{MHZ}$ in CST, while, in HFSS it's around $1.54 \mathrm{~dB}$ and $2.1 \mathrm{~dB}$ from 898 to $940 \mathrm{MHz}$. The values of $1.73 \mathrm{~dB}$ and $2.06 \mathrm{~dB}$ were observed at $915 \mathrm{MHz}$ in CST and HFSS respectively. This result remains acceptable for the effective functioning of the antenna. 


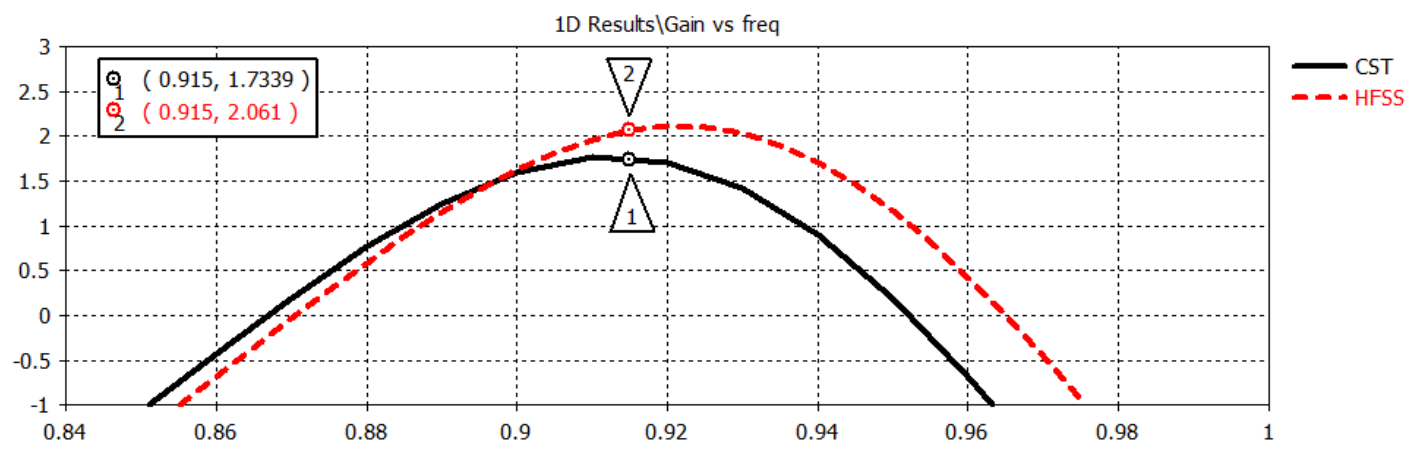

Figure 10. Peak gain of the propose antenna

\subsection{Comparison}

In order to emphasize the importance of miniaturization, a comparison between the proposed antenna with some other designed antennas in terms of antenna size, return loss frequency band, and corresponding gain are exhibited in Table 2, respectively.

Table 2. Comparison between the proposed antenna and antennas in [23-25]

\begin{tabular}{ccccc}
\hline Antennas & Dimensions $(\mathrm{mm} 3)$ & Return loss $(\mathrm{dB})$ & Frequency and Bandwidth $(\mathrm{MHz})$ & Gain $(\mathrm{dBi})$ \\
\hline$[27]$ & $107 \times 57 \times 12.8$ & -17.8 & $916-930(14 \mathrm{MHz})$ & $1.8(925 \mathrm{MHz})$ \\
{$[28]$} & $87 \times 87 \times 4.572$ & -19 & $888-923(35 \mathrm{MHz})$ & $4.55(911 \mathrm{~Hz})$ \\
{$[29]$} & $81 \times 58 \times 1.6$ & -16 & $905-930(25 \mathrm{MHz})$ & $2.96(915 \mathrm{MHz})$ \\
Proposed antenna & $68 \times 66 \times 1.6$ & -17 & $889-939(40 \mathrm{MHz})$ & $1.73(915 \mathrm{MHz})$ \\
\hline
\end{tabular}

The comparative table shows that the dimensions of the proposed slotted antenna are smaller than the other ones which mean that our antenna has the largest compactness with respect to conventional RFID UHF antenna dimension. In fact, the results shows that the return loss is almost similar to the other antennas. Our antenna also offers the better impedance bandwidth compared to the others. Even though it has the small gain, due to the size, it remains a good gain and acceptable for RFID UHF applications. The proposed antenna in this investigation is simply fabricated using the low-cost FR4 substrate with a compact size, a good impedance bandwidth and a good gain. It can be easily integrated with other devices and it is suitable for RFID UHF handling applications.

\section{CONCLUSION}

In this work, a new compact antenna with rectangular slots for UHF RFID handheld reader has been proposed, constructed, and tested. The slot technique allowed us to have a miniature patch antenna that can operate in the UHF RFID band. The antenna configuration, conception, simulated and measured results have been well argue. Based on these results, the proposed antenna has an operating frequency band ranging from 889 to $939 \mathrm{MHz}$ with a bandwidth of $40 \mathrm{MHz}$ and has a good performance in the targeted RFID UHF bands (USA band, Chinese band and Korea and Japan bands). The gradual introduction of slots brings an enhancement of antenna feature and allows reducing her size. The advantage of our antenna lies in the fact that it is compact and has a low profile. His size is reduced about $60 \%$ compared with conventional RFID UHF antenna. This antenna has a compact size $(68 \times 66 \times 1.6 \mathrm{~mm} 3)$, low cost and can be easily fabricated and integrated with other devices. Simulated and experimental results indicate that the proposed antenna could lay hands on its application in mobile UHF RFID reader systems.

\section{REFERENCES}

[1] F. Paredes, G. Zamora, S. Zuffanelli, J.H. Martinez, F. Martin and J. Bonache, "Free-space and on metal dualband tag for UHF-RFID applications in Europe and USA", Progress In Electromagnetics Research, vol 141, pp. 577590, 2013.

[2] W. Ziyang, L. Jinhai, L. Hui and Y. Ying-Zeng, "A UHF RFID Antenna Using Double-Tuned Impedance Matching for Bandwidth Enhancement", Progress In Electromagnetics Research Letters, vol 70, pp. 59-66, 2017. 
[3] I. Tabakh, M. Jorio, N. El Amrani El Idrissi and T. Mazri, "Design and Optimization of a New Slotted Patch Antenna for RFID Applications", International Journal on Communications Antenna and Propagation (I.Re.C.A.P.), vol 6, Issue 1, February 2016.

[4] D. Paret, RFID en ultra et super hautes fréquences UHF-SHF Théorie et mise en œuvre, Collection Dunod 2008.

[5] B. Carbunar, M.K. Ramanathan, M. Koyuturk, C. Hoffmann and A. Grama, "Redundant-Reader Elimination in RFID Systems", 2005 Second Annual IEEE Communications Society Conference on Sensor and Ad Hoc Communications and Networks, IEEE SECON, September 2005, pp. 176-184.

[6] S. Neha and K. Vijay, "Microstrip Patch Antenna with cross-slot for UHF RFID Handheld Reader Applications", International Journal of Electrical \& Electronics Engineering (IJEEE), vol 1, Issue 4, pp. 30-33 August 2014.

[7] Z. Haifeng and L. Xiaoyan, "Antenna circuit design and simulation for the reader of $125 \mathrm{kHz}$ RFID", Int. Conf. Computer Science and Service System, Nanjing, pp. 507-510, 2012.

[8] J. Nummela, L. Ukkonen, L. Sydanheimo, M. Kivikoski, "13.56 MHz RFID antenna for cell phone integrated reader", IEEE Antennas and Propagation Society Int. Symp, pp. 1088-1091, 2007.

[9] S. Neha, A.K. Gautam and B.K. kanaujia, "Circularly polarized square slot microstrip antenna for RFID applications", International Journal of Microwave and Wireless Technologies, pp. 1 of 6.

[10] L. Berrich and L. Zenkouar, "Microruban Dipole Antenna for RFID Applications at $2.45 \mathrm{GHz}$ ", International Journal of Electrical and Computer Engineering (IJECE), Vol. 6, No. 6, December 2016, pp. 2891-2899.

[11] Padhi. S.K, Karmakar. N.C and Law. C.L, "Dual polarized reader antenna array for RFID application", IEEE Antennas and Propagation Society Int. Symp., Columbus, OH, vol 4, pp. 265- 268, 2003.

[12] Bo wang and wenqing wang, "A miniature tri-band RFID reader antenna with high gain for portable devices", International Journal of Microwave and Wireless Technologies, pp. 1 of 5, 2016.

[13] A. Sofi, K. Roky, M. Bouhorma and I.H. Baraka, "Novel Antenna for UHF RFID Tags: Design and Miniaturization", International Journal of Electrical and Computer Engineering (IJECE), Vol. 6, No. 1, February 2014 , pp. 75-80.

[14] "Regulatory status for using RFID in the EPC Gen2 (860 to $960 \mathrm{MHz}$ ) band of the UHF spectrum", 30 November 2016.

[15] Bing Wang, "A Compact Antenna Design for UHF RFID Applications", Progress In Electromagnetics Research Letters, vol 53, pp. 83-88, 2015.

[16] K.K. Parashar, "Design and Analysis of I-Slotted Rectangular Microstrip Patch Antenna for Wireless Application", International Journal of Electrical and Computer Engineering (IJECE), Vol. 4, No. 1, February 2014, pp. 31-36.

[17] Avisankar. R, Sunandan. B, Debasree. C.S, Partha. P.S and Santosh. K.C, "Compact multi frequency strip loaded microstrip patch antenna with spur-lines", International Journal of Microwave and Wireless Technologies, page 1 of 11,2016

[18] Chen, Z.N., Antennas for Portable Devices, John Wiley \& Sons Ltd, West Sussex, England, 2007.

[19] Bhunia. S, Sarkar. D, Biswas. S, Sarkar. P.P, Gupta. B, Yasumoto. K, "Reduced size small dual and multifrequency Microstrip antenna", Microw. Opt. Technol. Lett., vol 50, pp. 961-965, 2008.

[20] Z.H. Wu, F. Wei, X.W. Shi, and W.T. Li., "A compact quad band-notched UWB monopole antenna loaded one lateral l-shaped slot", Progress in Electromagnetics Research, vol. 139, pp. 303-315, 2013.

[21] A. Ferchichi, and A. Gharsallah. "A Circuit Model to an Encoche Coplanar Antenna for a Radio Frequency Identification", International Journal of Electrical and Computer Engineering (IJECE), 2013, pp. 386-391.

[22] M. Ihamji, E. Abdelmounim, H. Bennis, M. Hefnawi, and M. Latrach, "Design of Compact Tri-Band Fractal Antenna for RFID Readers", International Journal of Electrical and Computer Engineering (IJECE), vol. 7, no. 4, pp. 2036-2044, 2017.

[23] E. Ahmed, and E. Abdenacer, "Miniaturization of a printed dipole antenna using metamaterials for RFID UHF technology", 2018 IEEE International Conference on Advanced Communication Technologies and Networking (CommNet), 17 May 2018, Marrakech, Morocco.

[24] A. Ferchichi, A. Gharsallah, "A Novel Small Sierpenski Antennas". International Journal of Electrical and Computer Engineering (IJECE). 2013, pp. 436-440.

[25] Chen. W.S and K.Y. Ku, "Band-rejected design of the printed open slot antenna for WLAN/WiMAX operation", IEEE Trans. Antennas Propag., vol 56, Issue 4, pp. 1163-1169, Apr. 2008.

[26] D. Mitra, D. Das, and S.R. Bhadra Chaudhuri, "Bandwidth enhancement of microstrip line and cpw-fed asymmetrical slot antennas", Progress In Electromagnetics Research Letters, vol 32, pp. 69-79, 2012.

[27] K. Lertsakwimarn, C. Phongcharoenpanich and T. Fukusako, "Circularly Polarized Low-Profile Antenna for Radiating Parallel to Ground Plane for RFID Reader Applications", International Journal of Antennas and Propagation, Volume 2013, Article ID 349817, 10 pages.

[28] A. Gautam, A. Kunwar and B. Kanaujia, "Circularly Polarized Arrowhead-Shape Slotted Microstrip Antenna", IEEE Antennas and Wireless Propagation Letters, vol 13, 2014.

[29] Bing Wang, "A Compact Antenna Design for UHF RFID Applications", Progress In Electromagnetics Research Letters, vol 53, pp. 83-88, 2015. 


\section{BIOGRAPHIES OF AUTHORS}

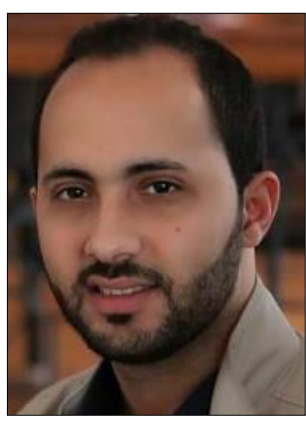

Younes El Hachimi was born in 1990. He received the master degree in Automatic, Signal processing, Industrial Computing from University Hassan first, Settat, Morocco, in 2014. He is currently a $\mathrm{PhD}$ student in Engineering, Industrial Management and Innovation research Laboratory, Faculty of Sciences \& Technology, Hassan first University, with a thesis on Contribution to the design of RFID antennas. His research interests include antennas, UHF and microwave radiofrequency identification (RFID).

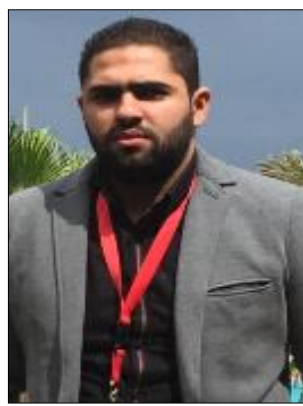

Yassine Gmih was born in 1991. He received the master degree in Automatic, Signal processing, Industrial Computing from University Hasn first, Settat, Morocco, in 2014. He is currently a $\mathrm{PhD}$ student in Engineering, Industrial Management and Innovation research Laboratory, Faculty of Sciences \& Technology, Hassan first University, with a thesis on Contribution to the design of RFID antennas. His research interests include antennas, UHF and microwave radiofrequency identification (RFID).

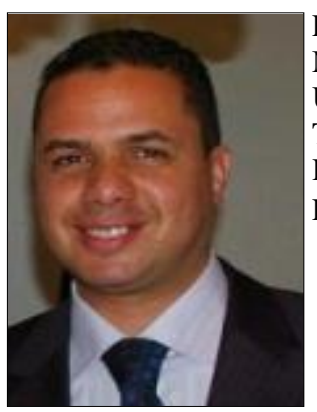

El Mostafa Makroum is Professor in the faculty of the sciences and technology of Settat, Morocco. He received his M.S. degree in 2007 from the Mohammadia School of Engineering, University Mohammed V, Rabat, Morocco. He received his Ph.D. degree in Computers and Telecommunications from the Higher National School of Electricity and Mechanics, University Hassan II, Casablanca, Morocco. His current research concerns RFID antennas, propagation and EMC problems.

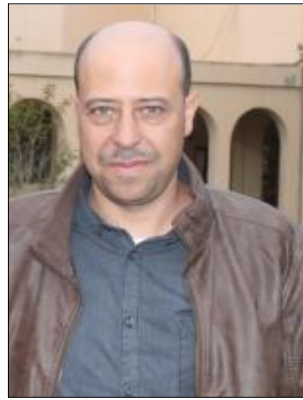

Abdelmajid Farchi Ing PhD in Electronis and Telecommunications Chiefs of research team Signals and Systems in Laboratory of Engineering, Industrial Management and Innovation. Educational person responsible of the cycle engineer Telecommunications and Embedded Systems to the faculty of the sciences and technology of Settat, Morocco. 